\title{
Avaliação de jogos sérios casuais usando o método GameFlow
}

\author{
Daniel Eugênio Neves ${ }^{1}$ \\ Luana Giovani Noronha de Oliveira Santos ${ }^{1}$ \\ Renata Cristina Santana ${ }^{1}$ \\ Lucila Ishitani ${ }^{1}$
}

\begin{abstract}
Resumo: Este trabalho apresenta uma análise da utilização do método GameFlow para avaliação de jogos sérios casuais. Esse método consiste em 35 heurísticas distribuídas nas seguintes áreas: concentração, desafio, imersão, interação social, habilidades do jogador, controle, objetivos claros e feedback. Para avaliação do método, foram selecionados três jogos casuais do site cerebromelhor.com que exercitam, em algum nível, as habilidades de memória, atenção, linguagem, raciocínio lógico e visão espacial. Os jogos são: "Não era bem este", "Costurando" e "Este sim, este não". Esses jogos foram testados por especialistas que avaliaram cada proposição estabelecida pelo método com notas no intervalo de 0 (não se aplica) a 4 (bom). Durante o processo, constatou-se que o método é aplicável a jogos casuais, mas algumas alterações foram propostas com o objetivo de contemplar as especificidades desses jogos.
\end{abstract}

Palavras-chave: Avaliação de jogos casuais. GameFlow. Heurísticas.

\begin{abstract}
This paper presents an analysis of the GameFlow method for evaluating casual games. This method consists of 35 heuristics distributed in the following areas: concentration, challenge, immersion, social interaction, player skills, control, clear goals and feedback. For the method evaluation, we selected three casual games from the site cerebromelhor.com which exercises the skills of memory, attention, language, logical reasoning and spatial vision. These games are: "Não era bem este", "Costurando" and "Este sim, este não". They were tested by experts who evaluated each proposition established by the method with notes in the interval from 0 (not applicable) to 4 (good). During the process it was found that the method is applicable for casual games, but some changes were recommended in order to address the specificities of these games.
\end{abstract}

Keywords: Evaluation of casual games. GameFlow. Heuristics.

\section{Introdução}

O conceito de jogos casuais tem sido amplamente discutido [1]. No entanto, embora existam diferentes definições, todas convergem para o fato de que um "jogo casual é fácil de aprender, fácil de jogar e oferece recompensas rápidas" [1], gerando uma experiência divertida. Além disso, o termo "jogos casuais", por vezes, refere-se ao fato de que o jogador casual pode jogá-lo sem grande esforço e sem se dedicar várias horas diárias $[1]$.

Por não exigirem muita atenção ou recursos específicos, os jogos casuais podem se tornar atividades secundárias, ou seja, enquanto joga, o jogador faz outra tarefa em paralelo: comer, assistir TV, ou falar ao telefone. Kultima [2] destaca que, por outro lado, a busca por esse gênero de jogo também pode ser motivada pela possibilidade de interação social e de exercício mental. Os jogos sérios, por sua vez, têm como característica

\footnotetext{
${ }^{1}$ Mestrado em Informática, PUC Minas, Rua Walter Ianni, 255 - São Gabriel - Belo Horizonte (MG) - Brasil

\{den.net@hotmail.com, luana.giovani@gmail.com, renata.cris.santana@gmail.com, lucila@pucminas.br
}

http://dx.doi.org/10.5335/rbca.2014.3244 
principal uma finalidade explícita e cuidadosamente pensada, que vai além da diversão; o que não significa que o jogo sério não seja divertido [3].

Sabe-se que o mercado de jogos e, principalmente, de jogos casuais, está crescendo a uma taxa de $20 \%$ ao ano [2] e, por essa razão, torna-se necessário pensar na avaliação desses jogos. Um dos métodos de avaliação de jogos denomina-se GameFlow [4] e se destina à avaliação de jogos digitais com vistas ao seu potencial de fornecer ao jogador uma experiência de diversão, gozo e prazer. Para a elaboração e validação desse método, foram aplicadas heurísticas relacionadas à usabilidade e à experiência do usuário. A teoria de fluxo (Flow Theory) [5], apresentada como principal fundamentação teórica para definição do GameFlow, afirma que um indivíduo encontra-se em estado de flow quando imerso, concentrado e envolvido em uma atividade. Diante disso, o objetivo deste artigo foi verificar se o método GameFlow é aplicável à avaliação de jogos casuais.

O primeiro passo consistiu em selecionar jogos casuais, com o objetivo de avaliá-los de acordo com o GameFlow para mensurar a aplicabilidade do método ao contexto dos jogos casuais. Em seguida, os jogos selecionados foram testados e avaliados por especialistas, sob uma metodologia predefinida e de acordo com os critérios estabelecidos pelo GameFlow. Os resultados da avaliação foram descritos, analisados e documentados. A avaliação desse conteúdo possibilitou a elaboração de um parecer sobre a aplicabilidade do método na avaliação de jogos casuais, o levantamento de possíveis adequações do método para tal finalidade e, ainda, embasou a produção de alguns apontamentos de melhorias para os jogos avaliados.

O presente artigo está estruturado da seguinte forma: a seção 2 apresenta os principais trabalhos relacionados; a 3 apresenta os critérios de avaliação de jogos segundo o GameFlow; a 4 trata dos jogos selecionados para avaliação segundo o GameFlow; a 5 apresenta os resultados da avaliação dos jogos; a 6 apresenta uma análise dos resultados obtidos e, finalmente, a seção 7 aborda as conclusões do trabalho realizado.

\section{Trabalhos relacionados}

Diversos trabalhos sobre avaliação de jogos sérios têm sido realizados. Mayer et al. [6] ressaltaram a importância de se ter um método avaliativo eficaz e propuseram um modelo de pesquisa conceitual, diante da qual alguns autores indicaram a necessidade de quantificar os dados apontados.

O método GameFlow, proposto por Sweetser e Wyeth [4], apresentou resultados eficientes no processo de avaliação de jogos, sendo, por isso, a base para o desenvolvimento de outros métodos e modelos. Seguindo essa linha, Jegers [7] avaliou jogos pervasivos utilizando como base o GameFlow, com alguns critérios excluídos e outros reformulados. Dessa forma, o método mostrou-se apropriado e promissor para entender a diversão nesse gênero de jogo. $\mathrm{Fu}, \mathrm{Su}$ e $\mathrm{Yu}$ [8], por sua vez, avaliaram jogos para e-learning e propuseram o modelo EGameFlow. Foram avaliados quatro jogos de uma universidade e questionários foram distribuídos para os estudantes. Os resultados evidenciaram a validade e efetividade do EGameFlow. Ding et al. [9] avaliaram jogos RTS, que são uma categoria especial de jogos computacionais com simulação militar. Para avaliação desses jogos, foi proposto o método de avaliação RTS-GameFlow, que também é uma extensão do GameFlow, com características específicas de jogos RTS: racionalidade, predição (planejamento), equilíbrio, estratégia e manipulação.

O modelo GameFlow também foi utilizado para avaliar outros tipos de jogos e aplicações, incluindo jogos móveis [10, 11], jogos de realidade virtual [12,13], jogos colaborativos e de simulação $[14,15,16]$.

\section{Critérios de avaliação do GameFlow}

Os critérios adotados pelo GameFlow, para avaliação de jogos digitais, estão contemplados em um total de oito categorias, empregadas na realização deste trabalho. Esta seção descreve cada uma delas.

\subsection{Concentração}

Para ser divertido, um jogo deve levar o jogador a se concentrar, pois o interesse é proporcional ao nível de concentração exigido por uma dada atividade. A atenção do jogador deve ser retida e mantida desde o início, o que pode ser obtido fornecendo-lhe algo de valor. A carga de trabalho deve aumentar, sem sobrecarregar o

Revista Brasileira de Computação Aplicada (ISSN 2176-6649), Passo Fundo, v. 6, n. 1, p. 45-59, abr. 201446 
jogador com tarefas que ele não julgue importantes. Contudo, é necessário manter um nível adequado às suas habilidades, considerando seus limites cognitivos e de memória. Durante o jogo, devem ser evitadas distrações não relacionadas à tarefa principal a ser realizada, como, por exemplo, configurações de jogo.

\subsection{Desafio}

O desafio é considerado um dos aspectos mais importantes de um bom projeto de jogo, uma vez que desafios maiores que a habilidade do jogador podem gerar ansiedade; já desafios menores podem gerar apatia, indiferença. Um ritmo apropriado no jogo possibilita pressão, mas não frustra o jogador. Por isso, o nível de dificuldade no jogo deve aumentar gradualmente, fornecendo desafios para melhorar a habilidade do jogador.

A satisfação no jogo está relacionada a tarefas relativamente difíceis, com obstáculos e desafios a serem superados pelos jogadores. A recompensa do desafio é intrínseca, pois o processo de transposição de obstáculos é a própria recompensa, por possibilitar a sensação de triunfo.

\subsection{Habilidades do jogador}

Um dos fatores essenciais ao estabelecimento de um estado de flow consiste na relação equilibrada entre as habilidades do jogador e os desafios a ele apresentados para o cumprimento de uma dada tarefa [4]. Suas habilidades devem ser possibilitadas e desenvolvidas pelo próprio jogo, seja pelo game play, seja por meio dos mecanismos de interação e controle disponibilizados ao jogador, ou, primordialmente, por ambos. É importante que o jogador desenvolva suas habilidades em relação ao jogo, jogando-o, pois isso tornará o processo divertido, prazeroso e desafiador.

Nesse sentido, o método GameFlow apresenta algumas possibilidades, técnicas e recursos que procuram levar o jogador a aprender o jogo enquanto joga: tutoriais que possam ser jogados como fases e com objetivos específicos, relacionados ao que o jogador encontrará ao longo do jogo; recursos de ajuda que deem suporte ao jogador sem que esse necessite deixar o jogo; aumento gradual dos desafios apresentados, levando, também, ao desenvolvimento gradual das habilidades do jogador; mecanismos de recompensa e reforço diante de desafios superados, objetivos alcançados e habilidades desenvolvidas.

Outro aspecto relevante consiste na interface e nos dispositivos de entrada do usuário. Ambos devem ser fáceis de compreender e utilizar, seguindo os padrões da indústria e utilizando-se de analogias com o mundo real. A interface de usuário deve facilitar o acesso do jogador às informações necessárias ao game play.

\subsection{Controle}

A sensação de controle é outro aspecto importante para levar o jogador a experimentar o estado de flow [4], como, por exemplo, o controle efetivo sobre elementos do universo do jogo, personagens e objetos, sobre os elementos da interface de usuário, sobre as informações relevantes para seus objetivos e sobre os dispositivos de entrada. Todos esses aspectos devem ser caracterizados pelo fácil aprendizado e pela capacidade de customização. Também são importantes os aspectos que se referem ao controle sobre o andamento do jogo, realizado por meio das possibilidades de interromper e retomar, salvar o estado do jogo e retornar a um estado anteriormente salvo. Ainda, nesse sentido, é importante a existência de mecanismos de prevenção e fácil recuperação de erros, evitando que a ocorrência desses possa impactar o game play ou mesmo interromper o funcionamento do jogo.

Além desses aspectos objetivos, perceber que suas ações e escolhas interferem no universo do jogo e modificam o game play cria no jogador a sensação de que é capaz de interferir nas próprias experiências, no universo do jogo e nas possibilidades de ação que lhe serão apresentadas. Assim, quanto mais o jogo permitir ao jogador jogá-lo da forma que desejar, mais o estará colocando como elemento central e mais the trará sensação de liberdade, controle e de capacidade de ação.

\subsection{Objetivos claros}

Um dos aspectos essenciais dos jogos consiste em seus objetivos. Há os objetivos principais, relacionados com a história ou contexto geral do jogo, objetivos relacionados a cada nível ou fase do jogo, e há, também, os 
relacionados a cada tarefa a ser cumprida. No entanto, para que se estabeleça um estado de flow, é necessário que esses sejam apresentados ao jogador de forma clara e em momentos apropriados [4]. Podem ser apresentados através de vídeos de animação (custscenes) introdutórios ao jogo ou entre suas fases [17], ou breves descrições do que deve ser realizado para cumprimento do próximo objetivo.

\subsection{Feedback}

É extremamente importante que o jogador receba feedbacks sobre suas ações e evolução no jogo a todo instante e no momento em que desejar. Sua pontuação deve estar acessível, assim como seu status no jogo. Os feedbacks fornecidos ao jogador irão auxiliá-lo a mensurar seu progresso em direção a um objetivo, a compreender em que errou e como pode se orientar na direção correta, assim como poderão encorajá-lo a melhorar seu desempenho [4]. Podem ser apresentados por meio de diferentes recursos, tais como efeitos sonoros e visuais, ou informações textuais exibidas na própria interface do jogo.

\subsection{Imersão}

Os indivíduos jogam para ter pensamentos e sentir emoções que não estão relacionadas ao mundo real, a um padrão social ou à sua vida cotidiana. Jogos devem transportar o jogador para um nível de envolvimento emocional e visceral, levando-os a esquecer que estão jogando. A imersão arrasta o jogador para dentro do jogo, afetando seu senso de tempo e do que ocorre em seu entorno. Efeitos sonoros e visuais são um bom recurso nesse sentido, assim como o enredo e o plano de fundo, que dizem quem são os personagens, qual o seu papel no universo do jogo e o que podem fazer, levando os jogadores a se sentirem como parte da história.

\subsection{Interação social}

Interação social não é um elemento do flow. No entanto, grande parte da atração por jogos online deve-se ao fato de haver uma comunidade virtual, na qual alguns jogadores passam horas batendo papo online com seus amigos, formando clubes e associações e ocupando o tempo melhorando seu personagem. Assim, jogos devem criar e suportar oportunidades que possibilitem interação social, como competição, cooperação e conexão entre os jogadores, além de possibilitar a interação por intermédio de chats e salas online.

\section{Jogos selecionados}

O site cerebromelhor.com disponibiliza, na forma de jogos casuais, um conjunto de exercícios mentais que, individualmente, trabalham com uma ou mais das seguintes habilidades: memória, atenção, linguagem, raciocínio lógico e visão espacial. Da série de jogos veiculados pelo site, cinco opções são gratuitas e podem ser jogadas online. Para este trabalho, foram selecionados três desses jogos que exercitam, em algum nível, as cinco habilidades citadas, conforme suas descrições, apresentadas no site. Além disso, esses jogos não têm nenhuma restrição de idade do jogador. Os jogos são: "Não era bem este", "Costurando" e "Este sim, este não". O objetivo pedagógico desses jogos e os desafios que apresentam foram os principais motivadores para sua escolha, pois são passíveis de análise sob a ótica de cada um dos critérios apresentados pelo GameFlow. Aliás, por pertencerem ao mesmo desenvolvedor, apresentam uma uniformidade tanto estética, quanto de interface e jogabilidade, reduzindo o número de variáveis que poderiam influenciar em sua avalição e comparação.

Para jogar, o jogador deve preencher as informações sobre sexo, escolaridade e ano de nascimento. Segundo observações feitas no próprio site, esses dados são usados para calcular o desempenho dos jogadores. $\mathrm{Na}$ tela inicial de cada um dos jogos, são apresentadas três opções: "Informações", "Exemplo" e "Iniciar". Na primeira opção, encontra-se uma explanação sobre os possíveis benefícios de se jogar o game. Na segunda, é dada uma explicação concisa de como se joga e a opção de visualizar a execução de um exemplo de jogada. Nesse momento, o jogo "Não era bem este" não oferece interação com o jogador, enquanto os jogos "Costurando" e "Este sim, este não" permitem que o jogador experimente o jogo após uma rápida demonstração. Após selecionar a opção "Iniciar", o usuário escolhe o nível de dificuldade, que muda de acordo com o jogo, conforme mostrado na Tabela 1. Após as configurações iniciais, há uma nova opção "Iniciar", que remete a uma síntese da explicação dada quando é selecionada a opção "Exemplo". Logo em seguida, inicia-se o jogo propriamente dito. 
Tabela 1: Nível de dificuldade dos jogos

\begin{tabular}{lcl}
\hline \multicolumn{1}{c}{ Jogo } & $\begin{array}{c}\text { Nível de } \\
\text { dificuldade }\end{array}$ & Configurações avançadas \\
\hline "Não era bem este" & 0 a 10 & $\begin{array}{l}7 \text { a } 9 \text { caracteres } \\
\text { Tipo de caracteres: "Egípcio", "Tailandês", "Runas", "Maia", } \\
\text { "Japonês" ou "Indiano". }\end{array}$ \\
"Costurando" & 0 a 6 & $\begin{array}{l}7 \text { a } 9 \text { letras } \\
\text { "Diagonais proibidas" ou "Diagonais permitidas". }\end{array}$ \\
"Este sim, este não" & 1 a 3 & Tamanho da matriz: 4x4, 5x5 ou 6x6. \\
\hline
\end{tabular}

O jogo "Não era bem este", ilustrado na Figura 1, propõe exercitar habilidades ligadas à memória, atenção e visão espacial. O objetivo do jogo é identificar caracteres que não foram exibidos previamente. Na primeira etapa, o jogador deve selecionar no lado direito os caracteres não encontrados do lado esquerdo. $\mathrm{O}$ caractere fica destacado com um “*”. Uma vez acionado o botão "Continuar", as marcações consideradas corretas são contornadas com a cor verde e as erradas com a cor vermelha. O tempo gasto pelo jogador é computado para cada etapa do jogo. Na segunda etapa, há um aumento no nível de dificuldade, pois os dois conjuntos não são mais exibidos lado a lado. Dessa forma, o primeiro conjunto é exibido sozinho na tela para que o jogador possa memorizá-lo. Depois de memorizar os caracteres, o jogador pode acionar o botão "Continuar" presente na interface. Acionado o botão "Continuar", o primeiro conjunto é removido, sendo então exibido o segundo conjunto, no qual o jogador deverá marcar, com um clique do mouse, aqueles caracteres que não estavam presentes no primeiro conjunto.

Figura 1: Jogo "Não era bem este"

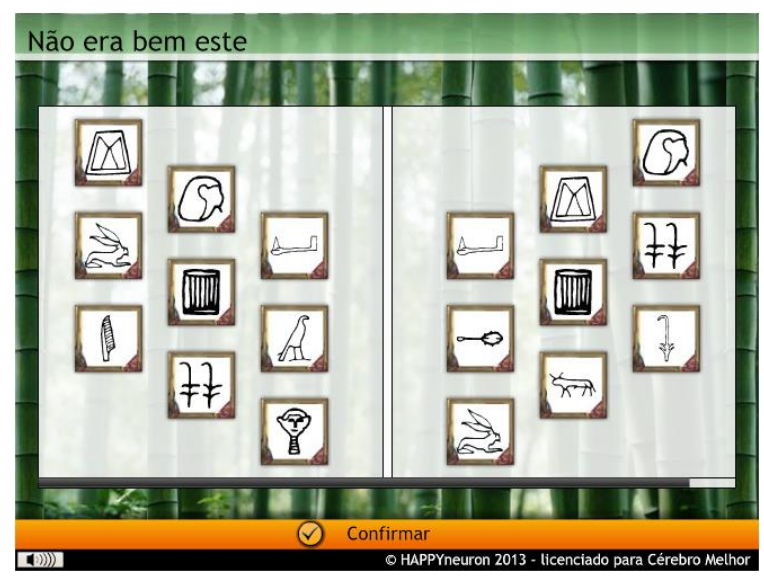

O jogo "Costurando" propõe exercitar habilidades relacionadas à linguagem e, em menor grau, ao raciocínio lógico, à visão espacial e à atenção. Nele, o jogador tem que encontrar quatro palavras dentre um conjunto de letras e para isso tem três chances. Caso o jogador não as localize na primeira tentativa, na segunda lhe será fornecida uma dica, que consiste na descrição do tópico ao qual a palavra está relacionada. Para a terceira tentativa, uma nova dica é fornecida ao jogador e consiste na marcação automática das duas primeiras letras da palavra. No início do jogo, é apresentada uma breve explicação sobre a quantidade de palavras a serem encontradas, o tempo e a regra a ser seguida. As palavras a serem encontradas não são compostas por letras alinhadas em uma mesma direção e sentido, como ocorre em um jogo de "caça-palavras". Ao contrário, as letras podem estar posicionadas de diferentes maneiras de forma contígua na horizontal, na vertical ou na diagonal. A Figura 2 ilustra essa disposição. A numeração ao lado das letras foi inserida para ilustrar a ordem em que elas foram selecionadas. 
Figura 2: Jogo "Costurando"

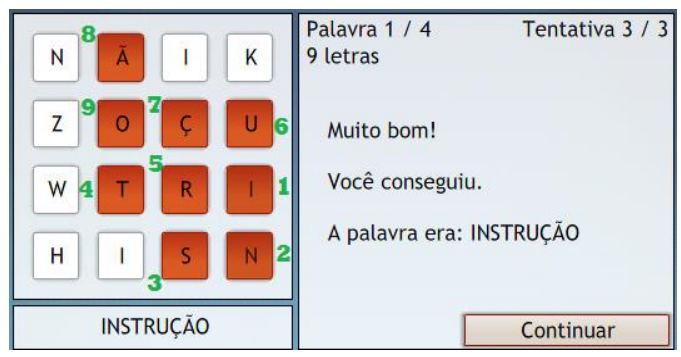

O jogo "Este sim, este não" propõe exercitar o raciocínio lógico, trabalhando também a atenção e a visão espacial. O game play é simples, sendo composto por apenas quatro rodadas de desafios. A cada rodada, é apresentado ao jogador um quadro, composto de quadros menores dispostos em uma matriz cujas dimensões podem ser de $4 \times 4,5 \times 5$ ou $6 \times 6$, dependendo do nível de dificuldade selecionado pelo jogador. Nesses quadros, são apresentados números pares e ímpares, aleatórios e diferentes a cada rodada (Figura 3). O objetivo do jogador é selecionar os números de acordo com as instruções que precedem cada uma das etapas e que permanecem visíveis ao lado do quadro numérico durante a interação do jogador. As possibilidades são: números pares e ascendentes, números pares e descendentes, números ímpares e ascendentes e números ímpares e descendentes. O primeiro número é marcado de laranja e o usuário deve clicar sobre ele para começar. Os números corretamente selecionados, segundo a ordem solicitada, são marcados de verde. Caso contrário, são marcados de vermelho por alguns segundos, voltando depois à cor normal. O desafio é acertar a série no menor tempo possível.

Figura 3: Tela inicial do jogo "Este sim, este não"

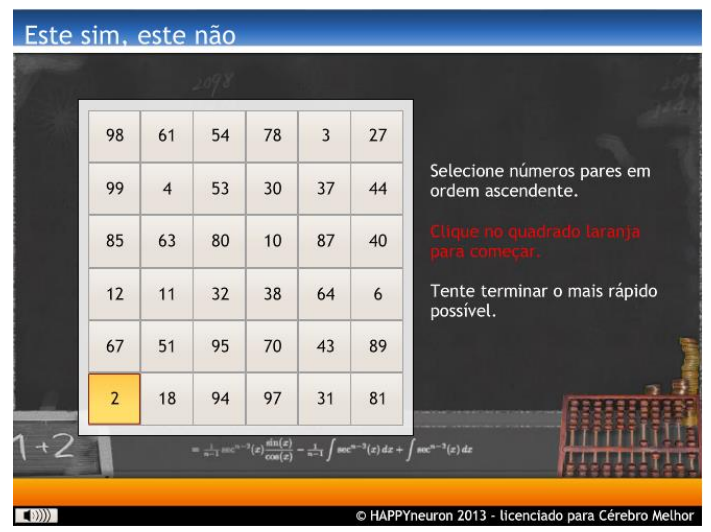

Sempre ao final dos jogos, é apresentado um ranking que compara o desempenho do jogador com os melhores desempenhos já obtidos por outros jogadores. Essa informação fica posicionada do lado direito da tela. Do lado esquerdo, encontram-se os valores medidos de precisão e tempo gasto, para os jogos "Não era bem este" e "Este sim, este não", e número de palavras encontradas e tempo de resposta para o jogo "Costurando".

\section{Avaliação dos jogos}

Esta seção apresenta os resultados de avaliação dos três jogos casuais citados, utilizando o método GameFlow (Tabela 2). Nas subseções que se seguem, serão apresentadas as avaliações de cada item, exceto os itens 7 (imersão) e 8 (interação social), uma vez que todos os três jogos possuem as mesmas características com relação a esses itens. Quanto à imersão, os três jogos possuem um game play curto, não há história ou background, os recursos sonoros e visuais são utilizados de forma simples e superficial e não há elementos, tais como a empatia com um personagem ou o envolvimento com a narrativa, que possibilitem um envolvimento emocional por parte do jogador. 
Tabela 2: Avaliação dos jogos selecionados

\begin{tabular}{|c|c|c|c|c|c|c|c|c|c|c|}
\hline \multirow{2}{*}{ Item } & \multirow{2}{*}{ Critério } & \multicolumn{3}{|c|}{ Avaliador 1} & \multicolumn{3}{|c|}{ Avaliador 2} & \multicolumn{3}{|c|}{ Avaliador 3} \\
\hline & & $\mathrm{M}$ & $\mathrm{L}$ & RL & $\mathrm{M}$ & $\mathrm{L}$ & RL & $\mathrm{M}$ & $\mathrm{L}$ & RL \\
\hline \multirow{7}{*}{ 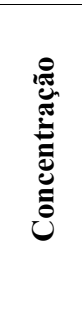 } & Jogo fornece grande quantidade de estímulos. & 2 & 2 & 2 & 2 & 2 & 3 & 2 & 2 & 2 \\
\hline & Jogo fornece estímulos que chamem atenção. & 2 & 1 & 2 & 2 & 2 & 3 & 2 & 2 & 3 \\
\hline & $\begin{array}{l}\text { A atenção do jogador é capturada rapidamente e seu foco é } \\
\text { mantido ao longo do jogo. }\end{array}$ & 3 & 3 & 3 & 2 & 3 & 3 & 2 & 2 & 3 \\
\hline & Jogadores não são sobrecarregados. & 4 & 4 & 4 & 3 & 3 & 3 & 4 & 4 & 4 \\
\hline & $\begin{array}{l}\text { A carga de trabalho é alta, porém adequada aos limites de } \\
\text { cognição, percepção e memória do jogador. }\end{array}$ & 3 & 2 & 4 & 3 & 2 & 3 & 3 & 2 & 3 \\
\hline & Jogadores permanecem atentos a tarefas importantes. & 3 & 4 & 4 & 2 & 3 & 3 & 4 & 4 & 4 \\
\hline & & 2,8 & 2,7 & 3,2 & 2,3 & 2,5 & 3,0 & 2,8 & 2,7 & 3,2 \\
\hline \multirow{5}{*}{$\begin{array}{l}\stackrel{0}{\tilde{Z}} \\
\stackrel{0}{0} \\
0\end{array}$} & Os desafios são adequados às habilidades do jogador. & 4 & 2 & 4 & 3 & 2 & 4 & 3 & 3 & 4 \\
\hline & Diferentes níveis de desafio são oferecidos. & 4 & 2 & 3 & 4 & 3 & 4 & 3 & 3 & 3 \\
\hline & $\begin{array}{l}\text { O nível de desafio aumenta à medida que o jogador progride } \\
\text { e melhora suas habilidades. }\end{array}$ & 3 & 1 & 1 & 3 & 2 & 3 & 3 & 2 & 3 \\
\hline & Novos desafios são fornecidos em ritmo apropriado. & 3 & 1 & 1 & 3 & 2 & 3 & 2 & 2 & 3 \\
\hline & & 3,5 & 1,5 & 2,3 & 3,3 & 2,3 & 3,5 & 2,8 & 2,5 & 3,3 \\
\hline \multirow{8}{*}{ 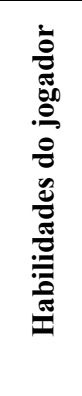 } & O jogador não precisa ler o manual para iniciar o jogo. & 3 & 4 & 4 & 3 & 3 & 3 & 4 & 4 & 4 \\
\hline & Aprender o jogo não é chato, mas sim divertido. & 4 & 3 & 4 & 2 & 2 & 3 & 3 & 2 & 3 \\
\hline & Há um help no próprio ambiente do jogo. & 4 & 2 & 4 & 4 & 4 & 4 & 4 & 4 & 4 \\
\hline & $\begin{array}{l}\mathrm{O} \text { aprendizado ocorre com tutoriais jogáveis e níveis } \\
\text { iniciais. }\end{array}$ & 4 & 3 & 4 & 2 & 2 & 3 & 1 & 2 & 3 \\
\hline & $\begin{array}{l}\mathrm{O} \text { aumento das habilidades do jogador ocorre em um ritmo } \\
\text { adequado ao seu progresso no jogo. }\end{array}$ & 4 & 1 & 3 & 3 & 1 & 3 & 2 & 1 & 4 \\
\hline & $\begin{array}{l}\text { O jogador é recompensado por seu esforço e } \\
\text { desenvolvimento de habilidades. }\end{array}$ & 1 & 1 & 1 & 1 & 1 & 1 & 1 & 1 & 1 \\
\hline & A interface e a mecânica do jogo são de fácil aprendizado. & 4 & 3 & 4 & 4 & 4 & 4 & 4 & 4 & 4 \\
\hline & & 3,4 & 2,4 & 3,4 & 2,7 & 2,4 & 3,0 & 2,7 & 2,6 & $\mathbf{3 , 3}$ \\
\hline \multirow{7}{*}{$\stackrel{\frac{0}{0}}{\stackrel{\Xi}{0}}$} & $\begin{array}{l}\text { ente-se no controle de personagens e de suas } \\
\text { o mundo do jogo. }\end{array}$ & 0 & 0 & 0 & 0 & 0 & 0 & 0 & 0 & 0 \\
\hline & O jogador sente-se no controle da interface. & 2 & 1 & 1 & 1 & 1 & 1 & 1 & 1 & 1 \\
\hline & $\begin{array}{l}\text { O jogador sente que pode controlar o andamento do jogo } \\
\text { (início, parada, saída, salvamento, etc.). }\end{array}$ & 2 & 2 & 2 & 2 & 2 & 2 & 2 & 2 & 2 \\
\hline & $\begin{array}{l}\text { O jogador não pode cometer um erro que prejudique o jogo } \\
\text { e encontra suporte, caso isso ocorra. }\end{array}$ & 4 & 3 & 4 & 4 & 4 & 4 & 4 & 4 & 4 \\
\hline & $\begin{array}{l}\text { O jogador sente que seus controles e ações são importantes e } \\
\text { que refletem no mundo do jogo. }\end{array}$ & 0 & 0 & 0 & 0 & 0 & 0 & 0 & 0 & 0 \\
\hline & $\begin{array}{l}\text { O jogador tem a sensação de controle sobre suas ações e } \\
\text { estratégias, e sente-se livre para jogar como quiser. }\end{array}$ & 1 & 1 & 1 & 1 & 1 & 1 & 1 & 1 & 1 \\
\hline & & 2,3 & 1,8 & 2 & 2 & 2 & 2 & 2 & 2 & 2 \\
\hline \multirow{3}{*}{ 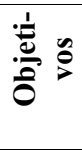 } & $\begin{array}{l}\text { Os objetivos principais do jogo são claros e apresentados } \\
\text { desde o início do jogo. }\end{array}$ & 4 & 4 & 4 & 4 & 4 & 4 & 4 & 4 & 4 \\
\hline & Os objetivos intermediários são claros. & 4 & 4 & 4 & 4 & 4 & 4 & 4 & 4 & 4 \\
\hline & & 4 & 4 & 4 & 4 & 4 & 4 & 4 & 4 & 4 \\
\hline \multirow{4}{*}{ ذँّ } & & 2 & 2 & 2 & 2 & 2 & 2 & 2 & 2 & 2 \\
\hline & $\mathrm{O}$ jo & 2 & 1 & 3 & 3 & 2 & 4 & 1 & 1 & 3 \\
\hline & Status e pontuação estão disponíveis ao jogador. & 1 & 2 & 1 & 1 & 1 & 1 & 1 & 1 & 1 \\
\hline & & 1,7 & 1,7 & 2,0 & 2,0 & 1,7 & 2,3 & 1,3 & 1,3 & 2,0 \\
\hline \multirow{5}{*}{ 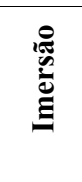 } & O jogador torna-se menos consciente do que ocorre ao redor. & 3 & 2 & 2 & 2 & 2 & 3 & 2 & 2 & 2 \\
\hline & O jogador torna-se menos consciente de si mesmo. & 1 & 1 & 1 & 1 & 2 & 3 & 2 & 2 & 2 \\
\hline & O jogador é envolvido emocionalmente no jogo. & 0 & 0 & 0 & 0 & 0 & 0 & 0 & 0 & 0 \\
\hline & O jogador é envolvido visceralmente no jogo. & 0 & 0 & 0 & 0 & 0 & 0 & 0 & 0 & 0 \\
\hline & & 2,0 & 1,5 & 1,5 & 1,5 & 2,0 & 3,0 & 2,0 & 2,0 & 2,0 \\
\hline \multirow{4}{*}{ 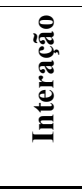 } & $\begin{array}{l}\text { Jogo dá suporte à competição e à cooperação entre } \\
\text { jogadores. }\end{array}$ & 1 & 1 & 1 & 1 & 1 & 1 & 1 & 1 & 1 \\
\hline & Jogo dá suporte à interação social (chat, etc.). & 1 & 1 & 1 & 1 & 1 & 1 & 1 & 1 & 1 \\
\hline & Há suporte a comunidades, dentro e fora do jogo. & 1 & 1 & 1 & 1 & 1 & 1 & 1 & 1 & 1 \\
\hline & & 1,0 & 1,0 & 1,0 & 1,0 & 1,0 & 1,0 & 1,0 & 1,0 & 1,0 \\
\hline
\end{tabular}

Legenda:

$\mathrm{M}=$ jogo de memória, $\mathrm{L}=$ jogo de linguagem, $\mathrm{RL}=$ jogo de raciocínio lógico

$0=$ não se aplica, 1 = deveria ter, mas não tem, $2=$ ruim, $3=$ médio, $4=$ bom 
No que se refere à interação social, nenhum dos jogos oferece recursos, tais como competição ou colaboração entre jogadores, conversas em chats ou em comunidades relacionadas ao jogo. O único recurso oferecido é que, no fim do jogo, todos exibem um ranking com as pontuações médias, o que possibilita uma comparação do desempenho de um jogador com o de outros jogadores, permitindo assim uma competição indireta.

\subsection{Avaliação do jogo de memória "Não era bem este"}

\subsubsection{Concentração}

Apesar de não oferecer muitos estímulos visuais ou auditivos que prendam a atenção do jogador, esse jogo exige que se compare e memorize diferentes formas, o que implica um índice elevado de concentração. As tarefas a serem realizadas são claras e nada mais é apresentado ao jogador além daquilo que precisa fazer, o que se constitui em um aspecto positivo para auxiliá-lo na manutenção de sua concentração. Todavia, a carência de estímulos, devida em parte à simplicidade gráfica do jogo e à utilização limitada de recursos sonoros, uma vez que exibe sempre o mesmo som, independente do resultado da interação do usuário, não auxilia na manutenção da atenção do jogador em relação à tarefa que está realizando, o que, por consequência, interfere em sua concentração.

\subsubsection{Desafio}

O jogo oferece duas possibilidades de configuração para o nível de dificuldade: alterar a quantidade de peças e aumentar ou diminuir o nível de complexidade de acordo com a escolha do usuário. Dessa forma, permite uma melhor adequação do nível de desafio a diferentes jogadores. Contudo, essas possibilidades são limitadas e podem se esgotar deixando de oferecer novos desafios para o jogador.

O jogo apresenta desafios diferentes ao jogador em cada uma de suas duas etapas: na primeira, os grupos de caracteres a serem comparados são exibidos lado a lado, o que privilegia a capacidade de comparação. Na segunda etapa, cada grupo é exibido isoladamente, exigindo esforço de memorização. Todavia, o nível de dificuldade dá um salto relevante entre uma etapa e outra. Esse fator pode se concretizar como algo chato, desmotivador, pois levará os jogadores a errarem mais na segunda etapa.

\subsubsection{Habilidades do jogador}

Diferentes formas de instrução são apresentadas ao jogador, dentre as quais, apenas o exemplo é opcional e as demais são desnecessárias e repetitivas. Logo, é possível iniciar o jogo lendo o mínimo de instruções e aprendendo o game play enquanto se joga. Da mesma forma, não é necessário que o jogador abandone o jogo para acessar um help, ou demais recursos necessários para auxiliá-lo.

É perceptível o desenvolvimento das habilidades do jogador à medida que são exercitadas durante jogadas consecutivas. Porém, há um aumento muito grande no nível de dificuldade entre a primeira e a segunda etapa do jogo, o que pode comprometer o equilíbrio necessário entre habilidades adquiridas e novos desafios apresentados. Além disso, o jogador não é recompensado pelo desenvolvimento de habilidades, as quais apenas interferem nos resultados exibidos ao final do jogo. utilização.

A interface é simples, clara e objetiva, permitindo que o jogador não encontre dificuldades em sua

\subsubsection{Controle}

Devido à simplicidade da mecânica do jogo e às suas características de jogo casual, grande parte dos itens de avaliação do quesito "Controle", conforme apresentados no modelo do GameFlow, não se aplica a essa avaliação. Algumas possibilidades que ficam evidentes são aquelas relacionadas ao controle do andamento do jogo. O jogador é capaz de iniciar o jogo no momento em que desejar; confirmar a seleção de um conjunto de caracteres mesmo que o tempo para a tarefa não tenha se esgotado; aguardar antes de iniciar um novo desafio ou 
nova etapa e reiniciar o jogo. Porém, ao iniciar uma etapa, o jogador deve, necessariamente, segui-la até o final, ainda que esteja prevendo um resultado ruim.

Durante a avaliação, não foram percebidos erros no software ou a possibilidade de erros que possam ser cometidos pelo jogador e que venham influenciar na jogabilidade ou no funcionamento do jogo.

\subsubsection{Objetivos claros}

Os objetivos do jogo são colocados de forma clara, simples e direta. O objetivo principal é fornecido assim que o usuário acessa o jogo e antes de começar a jogá-lo. Posteriormente, antes de cada etapa, há uma caixa de instruções na qual a tarefa a ser cumprida é claramente descrita.

\subsubsection{Feedback}

Ao longo do jogo, praticamente, não são fornecidos feedbacks para as ações do jogador nem sobre seu progresso. Os únicos feedbacks fornecidos ocorrem ao final de cada etapa e se referem aos caracteres que foram marcados equivocadamente ou que não foram marcados quando deveriam, o que condiz com o game play proposto. Apenas ao final do jogo, são exibidas informações sobre o desempenho do jogador em relação a outros jogadores.

\subsection{Avaliação do jogo de linguagem "Costurando"}

\subsubsection{Concentração}

O jogo não oferece muitos estímulos que auxiliem na concentração do jogador. Apresenta interface simples em formas, elementos visuais e cores. Não possui música e os efeitos sonoros são poucos e muito pontuais. Em algumas situações, esses aspectos podem prejudicar na manutenção da concentração: como os elementos visuais não textuais, os quais são poucos e pobres, já os elementos textuais tendem a ser mais chamativos aos olhos do jogador. Com isso, sua atenção tende a estar focada no quadro de letras e ele pode não perceber o movimento sutil da linha do tempo. Este fator é reforçado pela disposição dos elementos na interface: o quadro de letras encontra-se na posição superior esquerda, ponto privilegiado pelo sentido de leitura ocidental, enquanto a linha do tempo está no lado oposto, no canto inferior direito. Isso indica a possibilidade de revisão dos elementos dispostos na interface com vistas a um melhor agrupamento de informações correlatas.

A atenção do jogador é capturada de forma rápida. Quanto às tarefas a serem realizadas, o jogador não precisa fazer nada além do que necessita para jogar e não há nada que possa distraí-lo daquilo em que precise se concentrar. Porém, a cada tentativa de se identificar uma palavra, a carga de trabalho é muito alta, devido ao grande número de combinações possíveis das letras do quadro, que podem ser contíguas em qualquer direção e sentido. Isso pode levar a maioria dos jogadores a desistir de encontrar uma determinada palavra. Além disso, muitas vezes, as palavras sorteadas, ou são complexas, ou pertencem a um vocabulário restrito a uma área do conhecimento.

\subsubsection{Desafio}

Quanto aos desafios apresentados ao jogador, há diversas questões que podem impactar o jogo negativamente. O jogador pode configurar o nível de dificuldade no início do jogo, modificando os dois únicos parâmetros possíveis e cujas possibilidades de variação são pequenas. O primeiro parâmetro refere-se ao número de letras que irá compor as palavras a serem identificadas e que varia de sete a nove. $\mathrm{O}$ segundo parâmetro habilita ou não o uso de letras contíguas na diagonal, para composição das palavras. Uma vez definido o nível de dificuldade, seu impacto sobre o nível de desafio será constante durante todo o jogo, não podendo ser mais alterado. Diante desses aspectos, percebe-se que o jogo apresenta um nível alto de desafio, que não se dá de forma crescente, mas sim com uma base constante e implicações aleatórias do início ao fim do jogo. Desse modo, o nível de desafio não condiz com os limites dos jogadores, tornando-se muito difícil logo no início e desmotivando a participação efetiva. 
As palavras solicitadas em cada rodada costumam ser complexas e, muitas vezes, pertencem a vocabulários restritos a determinados níveis de conhecimento em áreas específicas. Por exemplo, em um dado momento dos testes, a dica dada foi de que a palavra pertencia ao tópico "Geologia". Um usuário leigo pensa em termos como mineração, magnesita, dentre outros mais comuns. Não acertando a palavra, é apresentada a terceira dica, que marca automaticamente as letras "s" e "u". Nesse ponto, ou o jogador conhece o jargão técnico da Geologia, ou descobrirá, frustrado, que a palavra escondida era "subducção". Outro exemplo do problema citado ocorreu quando a dica de tópico era "Floresta" e a palavra era "Sassafrás", como pode ser observado na Figura 4.

Figura 4: Tela inicial do jogo "Este sim, este não"

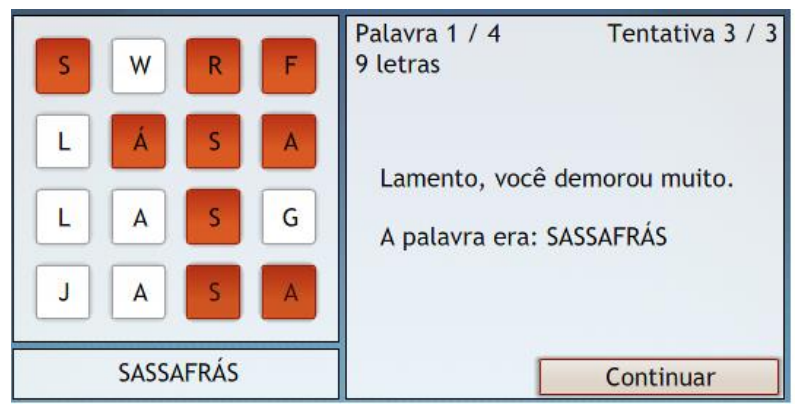

Outro problema com relação às dicas, e que torna o jogo ainda mais difícil, é o fato de que a apresentação do grupo ao qual a palavra supostamente pertenceria nem sempre tem uma relação clara com a palavra a ser encontrada. A Figura 5 ilustra exemplos de relações tópico-palavra apresentadas durante os testes.

Figura 5: Exemplo de relações entre tópicos e palavras

Exército $\rightarrow$ principal $\quad$ Sociologia $\rightarrow$ afinidade $\quad$ Mente humana $\longrightarrow$ conclusão Astrologia $\rightarrow$ simbólica

\subsubsection{Habilidades do jogador}

Diferentes formas de instrução são apresentadas ao jogador. Dentre elas, apenas o exemplo, que é interativo, é opcional e as demais acabam se tornando desnecessárias e repetitivas. Todavia, é possível iniciar o jogo lendo-se o mínimo de instruções e aprendendo o game play enquanto se joga. Da mesma forma, não é necessário que o jogador abandone o jogo para acessar um help, ou demais recursos necessários para auxiliá-lo. Porém, há certa dificuldade para que o jogador acostume-se com a mecânica do jogo e sinta-se um pouco mais confortável durante o game play, o que é minimizado caso o jogador tenha recorrido às instruções apresentadas.

O nível de dificuldade não é condizente com as habilidades dos jogadores, pois o jogo começa em um nível elevado para jogadores iniciantes. Além disso, a quantidade de combinações possíveis torna necessário que o jogador treine muito para conseguir resultados um pouco melhores. Acrescenta-se o fato de que muitas palavras são complexas e distantes da dica referente ao tópico ao qual pertenceriam, conforme exemplificado na seção 5.2.2.

O jogador não é recompensado ao acertar uma palavra e o sistema de dicas acaba "recompensando" aquele que erra. Ao se analisar a maneira como as dicas são empregadas, percebe-se que, por não ter conseguido acertar, o jogador receberá uma dica que o ajudará na próxima tentativa. Isso pode induzir o jogador a, simplesmente, não se esforçar na primeira tentativa, recebendo a dica na próxima.

\subsubsection{Controle}

Devido à simplicidade da mecânica do jogo e às suas características de um jogo casual, grande parte dos itens de avaliação do quesito "Controle", conforme apresentados no modelo do GameFlow, não se aplica a esta avaliação. Algumas possibilidades que ficam evidentes são aquelas relacionadas ao controle do andamento do jogo. O jogador é capaz de iniciar o jogo no momento em que desejar; aguardar antes de iniciar um novo desafio e reiniciar o jogo ao final de todos os desafios. Porém, uma vez iniciada uma etapa não é possível interrompê-la, alterar configurações ou sair do jogo, até que esteja concluída. Além disso, o delimitador para encerrar a jogada é 
o tempo. Ainda que o jogador tenha reconhecido uma dada palavra, precisa aguardar até o término do tempo que foi estipulado.

Durante o game play, o único controle disponível é apresentado na interface de usuário com o nome "Apagar tudo" e permite que o jogador desfaça todas as seleções de letras que tenha feito até então. Contudo, esse elemento continua visível ao final de uma rodada, mesmo estando bloqueado.

Em um dado momento dos testes ocorreu um erro. Ao final da segunda tentativa, as letras marcadas pelo jogador permaneceram assim, sendo que as letras que comporiam a terceira dica estavam exatamente entre as letras já marcadas, ficando o jogador impossibilitado de perceber quais seriam afinal as duas letras iniciais da palavra a ser encontrada.

\subsubsection{Objetivos claros}

Os objetivos do jogo são colocados de forma clara, simples e direta. O objetivo principal é apresentado assim que o usuário acessa o jogo e antes de começar a jogá-lo. Posteriormente, antes de cada etapa, há uma caixa de instruções na qual a tarefa a ser cumprida é claramente descrita. É possível aprender o jogo jogando de forma didática e efetiva.

\subsubsection{Feedback}

Praticamente, não são fornecidos feedbacks para as ações do jogador. Esse apenas recebe os "parabéns" por ter encontrado a palavra no quadro de letras ou é informado de que "demorou muito", momento no qual a palavra correta é exibida.

Quanto ao seu progresso, o jogador pode visualizar a todo o tempo a quantidade de palavras encontradas e quantas faltam, assim como o número de tentativas que já realizou para encontrar a palavra atual e de quantas ainda dispõe. Nenhuma informação sobre score ou status lhe é exibida no decorrer do jogo. Ao final de todas as etapas, é apresentada uma análise do desempenho do jogador em relação a outros jogadores.

\subsection{Avaliação do jogo de raciocínio lógico "Este sim este não"}

\subsubsection{Concentração}

O jogo não oferece muitos estímulos que auxiliem na concentração do jogador. Apresenta interface simples em formas, elementos visuais e cores. Não possui música e os efeitos sonoros são poucos e muito pontuais. Há momentos em que esses aspectos podem prejudicar na manutenção da concentração: os tons de cinza utilizados no quadro numérico não contribuem para estimular a percepção e acuidade visual, estando muito distante da faixa de frequências luminosas próximas ao amarelo, verde e vermelho e suas intermediárias, que oferecem mais estímulos para o tipo de atividade proposta $[18,19]$. O silêncio, nesse caso, priva o jogador do estímulo positivo que lhe seria proporcionado por uma atividade rítmica e uma melodia de acordes atrativos que pudessem suscitar a sensação de excitação, movimento e euforia [20].

A atenção do jogador é capturada de forma rápida pelo jogo. Os números já selecionados pelo usuário recebem um destaque visual muito sutil. O preto menos saturado dos números em sobreposição ao cinza do fundo não proporciona um contraste que auxilie o jogador na leitura do número, exigindo um esforço visual para sua percepção e diferenciação, privando-o de concentrar seus esforços essencialmente na atividade cognitiva necessária. Quanto às tarefas a serem realizadas, não há nada no jogo que possa distrai-lo daquilo em que precise se concentrar. O jogo possui uma carga de trabalho elevada, exigindo considerável esforço cognitivo, atenção e concentração. Todavia, o nível de atividade mantém-se adequado ao nível de dificuldade selecionado pelo jogador segundo suas habilidades, o que o auxilia na manutenção de sua concentração.

\subsubsection{Desafio}

O jogo apresenta três diferentes níveis de dificuldade que possibilitam uma boa variação entre si. Uma vez selecionado um nível de dificuldade, que apenas determina o tamanho da matriz do quadro numérico, esse 
permanecerá ao longo das quatro rodadas de desafios, o que inviabiliza a experiência de um nível crescente de desafio ao longo do jogo por si só. Para experimentar níveis diferentes de desafio, o jogador precisa concluir o jogo e selecionar outro nível para as próximas quatro rodadas.

\subsubsection{Habilidades do jogador}

Dentre as instruções apresentadas ao jogador, há um exemplo de game play em forma de simulação com a qual o jogador interage como em uma pequena versão do jogo e um texto explicativo do game play. Todavia, o jogador pode facilmente iniciar o jogo sem recorrer a manuais, exemplos ou tutoriais, pois o game play é simples, seus objetivos são claros e sua mecânica de jogo é bastante intuitiva. Em síntese, aprender o jogo é uma tarefa simples e fácil. Porém, quanto a obter ajuda, não há um help ao qual o jogador possa recorrer durante o jogo, ficando restrito às informações e instruções recebidas previamente. No entanto, os objetivos para cada rodada permanecem visíveis ao lado do quadro numérico com o qual o jogador interage, fato que, aliado à simplicidade da mecânica do jogo, não impõe o help online como fator imprescindível.

O jogador recebe feedback imediato para suas ações por meio de sons diferentes para indicação de erro ou acerto e o nível de dificuldade, que pode ser configurado no início do jogo, é condizente com as habilidades dos jogadores. Esses, por sua vez, experimentam um aumento gradual de suas habilidades a cada rodada e a cada vez que repetem o jogo. Contudo, não há qualquer sistema de recompensa para seus esforços ao longo do jogo, ficando a cargo de cada jogador sentir-se motivado ou não com a perspectiva de receber uma classificação melhor ao final de todas as rodadas.

\subsubsection{Controle}

Devido à simplicidade da mecânica do jogo e às suas características de um jogo casual, grande parte dos itens de avaliação do quesito "Controle", conforme apresentados no modelo do GameFlow, não se aplica a esta avaliação. As possibilidades de controle que ficam evidentes são aquelas relacionadas ao andamento do jogo. $\mathrm{O}$ jogador é capaz de iniciar o jogo no momento que desejar; aguardar antes de iniciar um novo desafio ou nova etapa e reiniciar o jogo ao final de todos os desafios. Porém, uma vez iniciada a etapa, não é possível interrompêla, alterar configurações ou sair do jogo, até que esta esteja concluída. Se o jogador percebe, por exemplo, que a avaliação de seu desempenho já está bastante comprometida, não há como reiniciar, o que o obriga a concluir todas as rodadas, mesmo não se sentindo mais motivado devido ao baixo desempenho nas rodadas anteriores. Esse fator apresenta-se como elemento negativo por facilmente frustrar o jogador.

Quanto à interface e aos dispositivos de entrada, a capacidade de controle do jogador é quase nula. As posições dos elementos da interface são fixas e sua exibição não pode ser suprimida. Não são disponibilizadas ao jogador outras formas de controle, além do mouse, com configuração para destros.

No início de uma etapa, o primeiro número do conjunto a ser selecionado pelo jogador é apresentado previamente selecionado, com destaque em amarelo. O jogador deve dar um clique sobre esse número para dar início à rodada. Porém, todo o quadro numérico permanece visível, dando ao jogador tempo para identificação prévia da posição dos números subsequentes a serem selecionados conforme o desafio proposto. Tal fator possibilita burlar o desafio, o que compromete a proposta do jogo.

Não foram percebidos, nem possibilitados ao jogador, erros do software que possam prejudicar o funcionamento do jogo ou o game play.

\subsubsection{Objetivos claros}

Quanto aos objetivos do jogo, estes são colocados de forma clara, simples e direta. O objetivo principal é apresentado assim que o usuário acessa o jogo e antes de começar a jogá-lo. Posteriormente, antes do início do game play, há uma caixa de instruções na qual a tarefa a ser cumprida é claramente descrita. Além disso, os objetivos específicos de cada rodada permanecem visíveis durante o game play, ao lado do quadro numérico com o qual o jogador interage para seleção dos números necessários para completar o desafio. 


\subsubsection{Feedback}

Quanto às ações do jogador, apenas dois feedbacks visuais são fornecidos por meio de um destaque dado ao quadro que contém o número selecionado. Se o número está correto, o quadro é destacado com a cor verde até que um próximo número seja devidamente selecionado. Caso o número esteja errado, um breve destaque em vermelho é verificado no quadro, voltando, logo a seguir, à cor original . Apenas ao final do jogo são exibidas informações a respeito do desempenho do jogador.

\section{Análise da aplicação do método}

Analisando a Tabela 3 é possível observar que o método de avaliação GameFlow aplica-se aos jogos casuais, uma vez que cerca de $85 \%$ dos critérios estão presentes em tais jogos.

Tabela 3: Quantidade de critérios

\begin{tabular}{lcc}
\hline \hline Elemento & $\begin{array}{c}\text { Quantidade de critérios } \\
\text { do GameFlow }\end{array}$ & $\begin{array}{c}\text { Quantidade de critérios que se } \\
\text { aplicam aos jogos casuais analisados }\end{array}$ \\
\hline Concentração & 6 & 6 \\
Desafio & 4 & 4 \\
Habilidades do jogador & 7 & 7 \\
Controle & 6 & 2 \\
Objetivos claros & 2 & 2 \\
Feedback & 3 & 3 \\
Imersão & 4 & 2 \\
Interação social & 3 & 3 \\
Total & 35 & 29 \\
\hline
\end{tabular}

Com a aplicação do método GameFlow, foi possível identificar falhas nos jogos. Por exemplo, ao avaliar a interação social, percebeu-se que nenhum dos três jogos avaliados contempla esse quesito. A possibilidade de mecanismos de interação poderia constituir-se em mais um estímulo para os jogadores, além de potencializar o treinamento das habilidades propostas pelos organizadores do site cerebromelhor.com, uma vez que, indivíduos de diferentes espaços geográficos poderiam trocar experiências.

Com base no trabalho aqui apresentado e sendo a maioria dos critérios do GameFlow aplicável aos jogos casuais, algumas alterações no método são necessárias para uma avaliação mais ampla de jogos desse gênero, assim como, durante o estudo do método, percebeu-se que alguns fatores necessitam de uma descrição mais precisa. Ao se tratar das habilidades do jogador, é observado que esse, segundo o GameFlow, deveria ser capaz de iniciar o jogo sem a necessidade de qualquer informação prévia. Porém, uma questão deixa dúvidas, uma vez que se refere diretamente a um dos quesitos a serem empregados: o jogador não precisa ler um manual para jogar. Nesse sentido, pondera-se: qual é o significado adotado para o termo "manual"? Em resposta, tem-se que manual se trataria de um conjunto de páginas impressas contendo instruções detalhadas sobre o jogo, ou seria um conjunto de instruções às quais se pode recorrer para compreensão da mecânica, recursos e game play do jogo? Nesse contexto, surge ainda outra questão relevante: o que seria a interface do jogo?

Na descrição do componente do método relativo ao controle, todas as referências à interface são feitas em termos dos mecanismos de interação direta entre o jogador e o universo do jogo e como via de acesso às informações relativas ao game play e à mecânica do jogo. Tais fatores indicam que a interface do jogo é a interface do sistema, composta pelo heads-up display (HUD), dispositivos de entrada, botões, menus e demais recursos de controle e interação. Entretanto, durante a descrição dos resultados da aplicação do método para avaliação do jogo Lords of EverQuest, no item relativo ao controle, quando a interface está sendo avaliada, é questionada a qualidade visual dos modelos tridimensionais que representam as unidades do jogador. Nesse 
ponto, considera-se que há um nível elevado de detalhamento para modelos de personagens muito pequenos, dificultando sua diferenciação. Mas, como se pode observar, tal consideração trata de elementos que compõem diretamente o universo do jogo e seus elementos visuais, que são desconectados dos elementos até então entendidos como interface do jogo. Basta perceber que, em outras referências encontradas no método para tais fatores, descreve-se a interface como componente individualizado que pode, por exemplo, manter mesmo tamanho e resolução independente das opções fornecidas para a área de jogo. Diante disso, talvez seja necessário um elemento específico do método para avaliação de aspectos relacionados aos elementos visuais, sonoros e textuais do jogo, ao invés de apenas citá-los como componentes gerais que impactam nesse ou naquele elemento específico do método.

Um ponto que necessita ser esclarecido é a pontuação de 0 a 5 . Em nenhum momento de apresentação do GameFlow é explicitado o que cada ponto avalia exatamente. Esses valores foram descritos da seguinte forma: " 0 - N/A; 1 - not at all; 2 - below average; 3 - average; 4 - above average; 5 - well done". Tais termos são subjetivos, podendo gerar dúvidas ou interpretações ambíguas. Por esse motivo, durante os testes realizados, foi necessário restringi-los ao intervalo de 0 a 4 , considerando: 0 - N/A; 1 - deveria ter mas não tem; 2 - ruim; 3 médio; 4 - bom.

No elemento referente ao feedback, o primeiro critério possibilita mais de uma interpretação. Quando se fala em feedback sobre o progresso relacionado ao objetivo do jogo, não fica claro se esse retorno deve ser durante o jogo ou após a partida. Para este trabalho, o critério foi utilizado para avaliar o retorno sobre o jogo independente do momento em que é exibido ao jogador.

Cabe ainda observar que jogos casuais exigem um menor grau de imersão e de controle, ou seja, alguns critérios desse item de avaliação não se aplicam a esse gênero de jogo. São eles: controle sobre personagens e unidades, controle sobre o "mundo" do jogo, diferentes possibilidades de estratégias, envolvimento emocional, envolvimento "visceral".

\section{Conclusões}

Com base no trabalho realizado, é possível perceber que o método GameFlow pode ser aplicado para avaliação de jogos casuais, tendo como referência primeira seu potencial de fornecer ao jogador uma experiência de divertimento e prazer. Sua aplicação para avaliação dos jogos casuais selecionados permitiu identificar melhorias a serem implantadas nesses jogos, o que comprova os benefícios da utilização do GameFlow. No entanto, conforme exposto neste trabalho, é necessário modificar alguns critérios de classificação, para melhor compreensão de seu significado e melhor adequação ao contexto de jogos casuais sérios. Em alguns momentos, faz-se necessária maior clareza, ou definição mais precisa de fatores com certo grau de subjetividade, tais como "introdução visualmente espetacular", abordados pelos autores do método de maneira tal que parece pautada nas impressões, ou fruição dos próprios sujeitos envolvidos no desenvolvimento do método. Também se observou a inadequação de se avaliar a imersão dos jogadores, já que essa não é uma condição que se espera atingir, quando se joga um jogo casual.

Como trabalhos futuros, sugere-se a análise da aplicação de outros métodos de avaliação de jogos, para comparação de resultados e melhor adequação ou proposição de novo método de avaliação de jogos casuais sérios.

\section{Referências}

[1] KUITTINEN, J. et al. Casual games discussion. In: CONFERENCE ON FUTURE PLAY, 2007, Toronto, Canadá. Proceedings... New York, USA: ACM, 2007. p. 105-112.

[2] KULTIMA, A. Casual game design values. In: INTERNATIONAL MINDTREK CONFERENCE: Everyday Life in the Ubiquitous Era, 13, 2009, Tampere, Finlândia. Proceedings... New York, USA: ACM, 2009. p. 58-65. DOI=10.1145/1621841.1621854.

[3] MICHAEL, D.; CHEN, S. Serious games: games that educate train and inform. Boston: Thomson Course Technology, 2006.

Revista Brasileira de Computação Aplicada (ISSN 2176-6649), Passo Fundo, v. 6, n. 1, p. 45-59, abr. 201458 
[4] SWEETSER, P.; WYETH, P. GameFlow: a model for evaluating player enjoyment in games. Computers in Entertainment, v. 3, n. 3, July 2005. DOI $=10.1145 / 1077246.1077253$.

[5] CSIKSZENTMIHALYI, M. Flow: the psychology of optimal experience. New York: Harper Perennial, 1990.

[6] MAYER, I. et al. The research and evaluation of serious games: toward a comprehensive methodology. British Journal of Educational Technology, 2013.

[7] JEGERS, Kalle. Pervasive game flow: understanding player enjoyment in pervasive gaming. Computers in Entertainment, v. 5, n. 1, Article 9, Jan. 2007. DOI=10.1145/1236224.1236238.

[8] FU, F.; SU, R.; YU, S. EGameFlow: a scale to measure learners' enjoyment of e-learning games. Computers in Entertainment, v. 52, n. 1, Jan. 2009, p. 101-112. DOI=10.1016/j.compedu.2008.07.004.

[9] DING, Sha. et al. RTS-GameFlow: a new evaluation framework for RTS games. In: INTERNATIONAL CONFERENCE ON COMPUTATIONAL INTELLIGENCE AND SOFTWARE ENGINEERING, 2009. Proceedings... IEEE, 2009. p. 1-4. DOI: 10.1109/CISE.2009.5363526.

[10] YEE, S.; DUH, H.; QUEK, F. Investigating narrative in mobile games for seniors. In: SIGCHI CONFERENCE ON HUMAN FACTORS IN COMPUTING SYSTEMS. Proceedings... New York, USA: ACM, 2010. p. 669-672.

[11] OMAR, A.; ALI, N. M. Measuring flow in gaming platforms. Information retrieval, June, 2011. p. 302-305. DOI= 10.1109/STAIR.2011.5995806.

[12] FINKELSTEIN, S. et al. Astrojumper: motivating exercise with an immersive virtual reality exergame. Presence: Teleoperators and Virtual Environments, v. 20, n. 1, 2011. p. 78-92. DOI=10.1162/pres_a_00036.

[13] KHOO, E. T. et al. Age invaders: social and physical inter-generational mixed reality family entertainment. Virtual Reality, v. 12, n. 1, Mar. 2008. p. 3-16. DOI=10.1007/s10055-008-0083-0.

[14] FABER, J.P.; VAN DEN HOVEN, E. 2011. MARBOWL: increasing the fun experience of shooting marbles. Personal and ubiquitous computing, Jun. 2011. DOI=10.1007/s00779-011-0405-1.

[15] MORRISON, A. et al. Collaborative use of mobile augmented reality with paper maps. Computers \& Graphics. v. 35, n. 4, Aug. 2011. p. 789-799.

[16] KLIEM, A.; WIEMEYER, J. Comparison of a traditional and a video game based balance training program. International Journal of Computer Science in Sport, v. 9, n. 2, 2010. p. 80-91.

[17] EDUARDO, F. M. Conceitos estéticos-visuais dos jogos digitais. 2011. Dissertação (Mestrado) - Pontifícia Universidade Católica do Rio Grande do Sul, Porto Alegre.

[18] FOX, B. Game interface design. Thomson Course Technology PTR, 2005.

[19] ARNHEIM, R. Arte e percepção visual: uma psicologia da visão criadora. São Paulo: Pioneira, 1987.

[20] SOUZA, L. O. C. G. Aspectos da sonoplastia no teatro - A articulação do som em cena. Revista OuvirOuVer, v. 1, p. 95-103, 2005. 